\title{
Cardinal de Retz, Oeuvres complètes
}

\section{Benedetta Papasogli}

\section{(2) OpenEdition}

\section{Journals}

\section{Edizione digitale}

URL: https://journals.openedition.org/studifrancesi/26243

DOI: 10.4000/studifrancesi.26243

ISSN: 2421-5856

\section{Editore}

Rosenberg \& Sellier

\section{Edizione cartacea}

Data di pubblicazione: 1 avril 2007

Paginazione: $173-174$

ISSN: 0039-2944

\section{Notizia bibliografica digitale}

Benedetta Papasogli, «Cardinal de Retz, Oeuvres complètes», Studi Francesi [Online], 151 (LI | I) | 2007, online dal 30 novembre 2007, consultato il 22 novembre 2021. URL: http://journals.openedition.org/ studifrancesi/26243; DOI: https://doi.org/10.4000/studifrancesi.26243

Questo documento è stato generato automaticamente il 22 novembre 2021.

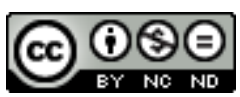

Studi Francesi è distribuita con Licenza Creative Commons Attribuzione - Non commerciale - Non opere derivate 4.0 Internazionale. 


\title{
Cardinal de Retz, Oeuvres complètes
}

\author{
Benedetta Papasogli
}

\section{NOTIZIA}

CARDINAL DE RETZ, Oeuvres complètes, Textes établis, avec introduction, notices, lexique des termes de rhétorique, bibliographie, reproductions de manuscrits, index des noms de personne, par Jacques DELON, t. I-IV, Paris, Champion, «Sources classiques», 2005.

1 Le opere complete del cardinal de Retz erano state edite alla fine dell'Ottocento nella collana dei Grands écrivains de la France, con una impostazione critica e storiografica su cui pesavano insieme la mentalità positivista e un certo preconcetto morale nei confronti del cardinale avventuriero. Si sta sviluppando ora una magnifica impresa editoriale che rinnova in profondità la conoscenza di un personaggio affascinante nelle sue stesse ambiguità, nel mistero psicologico dello scollamento fra il suo genio e il suo fallimento. Dei nove volumi programmati nella collana «Sources classiques», i Mémoires occuperanno gli ultimi due: potrà sembrare che i primi sette si prospettino come una lunga digressione in dimore secondarie, o una noiosa anticamera in attesa del capolavoro. Qualcuno persino si stupirà che l'opera di Retz sia a tal punto articolata. In realtà, i volumi sinora pubblicati dimostrano che tutti gli scritti di Retz sono necessari a ridefinire la posizione del nostro autore al crocevia dei generi letterari, e al cuore della secentesca età dell'eloquenza. Si può dire di più: è il fosco, avvincente romanzo della vita di Retz che si sviluppa, prima che nei Mémoires, nella massa di atri testi usciti dalla sua penna, grazie anche agli eccellenti apparati critici che incorniciano qui la restituzione testuale.

2 L'edizione si articola nel modo seguente: t. I, Oeuvres oratoires, politiques et religieuses; t. II, Discours philosophiques, controverses avec Desgabets sur le cartésianisme; dal t. III al VII si sviluppa la Correspondance, di cui sono apparsi per ora due tomi centrati rispettivamente - su L'affaire du cardinalat e sulle Lettres épiscopales degli oscuri anni della "fronda ecclesiastica". Il primo volume offre alcuni strumenti essenziali che riguardano l'intera edizione, tra cui una dettagliatissima cronologia, mentre 
introduzioni, bibliografie, indici, glossari, si diversificano accompagnando lo svolgersi dell'opera. L'insieme del corpus si presenta notevolmente rinnovato rispetto all'edizione ottocentesca, grazie alle ricerche erudite e fortunate che hanno permesso a Jacques Delon di fare "trouvailles" importanti, o di avvalersi di progressi della filologia e della critica: così i testi filosofici di Retz, ricostruiti in assenza dei manoscritti originali e ordinati arbitrariamente da Chantelauze e da Victor Cousin, ricevono nuova luce dai lavori di Geneviève Rodis-Lewis che ha pubblicato nel 1983 le Oeuvres philosophiques inédites di Desjabets, chiarendo un episodio finora oscuro nella storia del cartesianesimo.

Ognuno dei volumi ha specifiche ragioni di interesse, e mostra una diversa sfaccettatura nella personalità del cardinale. Dal primo tomo risalta quell'uomo della parola che Retz è stato principalmente, grande attore su una scena complessa che occorre conoscere a fondo per valutare un'oratoria non riducibile agli aspetti stilistici della scrittura. Le prese di parola di Retz nell'ambito politico e in quello religioso vanno d'altronde inquadrate nella storia dell'eloquenza profana e di quella sacra del tempo: le analisi di Jacques Delon evidenziano, nei due casi, l'originalità di Retz, con una chiara coscienza del radicale rinnovamento che l'ondata di studi sulla retorica classica ha apportato alla storiografia del Seicento letterario.

Più breve il corpus dei "discorsi filosofici" e delle controversie intorno a questioni cruciali del cartesianesimo - il rapporto anima-corpo, la definizione di sostanza, ecc. cui Retz si è dedicato durante gli anni di Commercy; particolarmente complesse le problematiche filologiche suscitate dai testi di queste dispute mai pubblicate finora per intero, ove si svela un profilo inatteso dell'inafferrabile volto: se le oeuvres oratoires manifestano in pieno la contemporaneità di Retz all'età dell'idealismo aristocratico, ecco che le controversie filosofiche, coeve alla stesura dei Mémoires, completano i Mémoires della loro parte mancante, la saggezza e la "hauteur", la dottrina e il distacco. Precipitiamo, invece, nel clima di un romanzo d'intrigo e di misteri, a fortissima suspence, con i volumi di corrispondenza, anche questi arricchiti di preziose scoperte di inediti che permettono di riscrivere in parte il racconto dei Mémoires (ad esempio, la famosa questione della "revoca" con cui Anna d'Austria si sarebbe opposta, troppo tardi, al cardinalato di Retz, leggenda abilmente intrattenuta in virtù di opposti interessi). Ed è soprattutto il quarto volume, con la corrispondenza di Retz prigioniero, e il braccio di ferro tra corte di Roma e corte di Francia intorno alla sorte di un uomo più che mai capace di occupare, dal fondo del suo carcere, la scena della storia, ad offrire un contrappunto di alto interesse alla lettura dei Mémoires. Sullo sfondo del conflitto tra potere politico e potere ecclesiastico, l'avventura individuale, eroica e sordida, sfiora degli "enjeux" di portata epocale. E già nella scrittura delle lettere s'intravede come la messa in scena della parola divenga, di fronte al naufragio delle ambizioni e delle passioni, una suprema compensazione. 